\title{
Hippocampal Neurochemical Pathology in Patients with Panic Disorder
}

\author{
Murad Atmaca $^{1}$, Hanefi Yildirim², M. Gurkan Gurok ${ }^{1}$, Muammer Akyol ${ }^{2}$ and Filiz Koseoglu' \\ ${ }^{1}$ Departments of Psychiatry and ${ }^{2}$ Radiology, Firat University, School of Medicine, Elazig, Turkey
}

\begin{abstract}
Objective In the present study, we measured hippocampal $\mathrm{N}$-acetyl-l-aspartate (NAA), choline (CHO) and creatine (CRE) values in patients with panic disorder and healthy control subjects using in vivo ${ }^{1} \mathrm{H}$ MRS.

Methods We scanned 20 patients meeting Diagnostic and Statistical Manual of Mental Disorders-IV (DSM-IV) criteria for panic disorder and 20 matched healthy controls with a 1.5 Tesla GE Signa Imaging System and measured of NAA, CHO, and CRE in hippocampal regions.

Results When NAA, CHO and CRE values were compared between groups, statistically significant lower levels for all ones were detected for both sides.

Conclusion Consequently, in the present study we found that NAA, CHO and CRE values of the patients with panic disorder were lower than those healthy controls. Future studies involving a large number of panic patients may shed further light on the generalizability of the current findings to persons with panic disorder.

Psychiatry Investig 2012;9:161-165
\end{abstract}

Key Words $\mathrm{N}$-acetylaspartate, Creatine, Choline, Panic disorder, ${ }^{1} \mathrm{H}$ MRS

\section{INTRODUCTION}

Panic disorder, which is classified as an anxiety disorder in Diagnostic and Statistical Manual of Mental Disorders, 4th ed. (DSM-IV), is a severe psychiatric disorder associated with significant impairment of the patients' quality of life as well as their social life function. Lifetime prevalence of panic disorder varies 1 to 3 percent of the general population. It is a chronic and often disabling anxiety disorder. Panic disorder has panic attacks in its clinical presentation.

Although important neurobiological investigations have been made, our knowledge on its pathophysiology has not been enough yet. On the other hand, there are very limited neuroimaging investigations in panic disorder. Most studies ${ }^{1-11}$ and Gorman's hypothesis ${ }^{12}$ suggest that the aberrancies in structure or function in prefrontal cortex, ACC, amygdala, hippocampus

Received: July 28, 2011 Revised: January 3, 2012

Accepted: January 12, 2012 Available online: April 30, 2012

$\triangle$ Correspondence: Murad Atmaca, MD

Firat (Euphrates) Universitesi, Firat Tip Merkezi, Psikiyatri Anabilim Dali, 23119 Elazig, Turkey

Tel: +90-424-233-3555/2282, Fax: +90-424-238-8096

E-mail: matmaca_p@yahoo.com

(a) This is an Open Access article distributed under the terms of the Creative Commons Attribution Non-Commercial License (http://creativecommons.org/licenses/by$\mathrm{nc} / 3.0$ ) which permits unrestricted non-commercial use, distribution, and reproduction in any medium, provided the original work is properly cited. may be closely related to the pathophysiology of panic disorder.

As for the functional brain investigations in panic disorder, first of all, we should mention about proton magnetic resonance spectroscopy ( ${ }^{1} \mathrm{H}$ MRS) which was also used in the present investigation. MRS is a safe and non-invasive means of measuring the brain chemistry and metabolism in vivo and has an increasing trend in the investigations of neuroimaging of psychiatric disorders. In MRS, following neurochemicals had been measured; $\mathrm{N}$-acetyl-l-aspartate (NAA; a marker of neuronal viability), glutamate and glutamine, choline ( $\mathrm{CHO}$; a marker of cell membrane turnover), myo-inositol, and creatine (CRE; a marker of cellular energy). Because a reduction of brain NAA is considered to reveal a loss of neurons and axons and/or neural dysfunction, with its effect on the neuronal integrity and viability one can be speculate that its more sensitivity to neuronal loss than structural magnetic resonance imaging (MRI) findings. ${ }^{13}$ Although several studies in patients with panic disorder revealed inconsistent results, dysregulation of the hypothalamic-pituitary-adrenal (HPA) axis may play a role in panic disorder. ${ }^{14}$ Hippocampus, a glucocorticoid feedback area, is highly sensitive to endogenous glucocorticoid levels and so is an important region affected by stress modulation organized by the hypothalamo-pituitary-adrenal axis (HPA). ${ }^{15-17}$ On the other hand, Massana et al..$^{18}$ performed a MRS study in patients with 
panic disorder and found that the concentration of creatine and phosphocreatine was significantly lower in the right medial temporal lobe region of panic disorder patients compared to healthy subjects while no significant differences between the two groups were observed in the medial prefrontal cortex. Moving from this point, as part of a larger effort to further characterize the role of the hippocampus in panic disorder which has been already emphasized, ${ }^{12}$ we performed a MRS investigation in which following neurochemicals had been measured; NAA (a marker of neuronal viability), $\mathrm{CHO}$ (a marker of cell membrane turnover), CRE (a marker of cellular energy) in hippocampus of the patients with panic disorder and hypothesized that hippocampal neurochemicals would change in this group of patients compared to healthy persons.

\section{METHODS}

Patients were selected among those with panic disorder according to DSM-IV belonging to our another unpublished study. Thus, 20 patients were invited to participate in the present study and seventeen accepted. The Structured Clinical Interview for the DSM-IV (SCID) ${ }^{19}$ and the Hamilton Depression Rating Scale (HDRS), which determines the severity of the depressive symptoms, ${ }^{20}$ and Panic Agoraphobia Scale (PAS) ${ }^{21}$ were used to assess participants. The patients were initially screened for potential inclusion in the present study before being further screened for inclusion in the MRS study. Healthy volunteers were recruited from the hospital staff. This study was carried out under guidelines of Helsinki Declaration. Written informed consent was obtained from all subjects.

The subjects were excluded if any of them have the presence of any current comorbid psychiatric disorder apart from depressive disorder, current medical problems, or alcohol/substance abuse within the 6 months preceding the study. Of the patients, two met criteria for major depressive disorder while following lifetime comorbidities were determined: social anxiety disorder $(\mathrm{n}=1)$, hypochondriasis $(\mathrm{n}=1)$, and obsessive compulsive disor$\operatorname{der}(n=1)$. Matched controls were selected among those who had no DSM-IV Axis I disorders in self or in a first-degree relative, as determined by the SCID non-patient version, no current medical problems, neurologic or psychiatric histories, and no use of psychoactive medication.

\section{MRI procedure}

Magnetic resonance imaging was conducted at the Firat University Hospital, Department of Radiology, Center of Neuroradiology at a 1.5-Tesla GE signa Excite high speed scanner (Milwakuee, USA). With the following parameters, MRI scans were obtained: repetition time $(\mathrm{TR})=2000 \mathrm{~ms}$, echo time $(\mathrm{TE})=15.6$ $\mathrm{ms}$, field of view $(\mathrm{FOV})=240 \mathrm{~mm}$, flip angle $=20^{\circ}$, bandwidth $=$
20.8 , slice thickness $=2.4 \mathrm{~mm}$, echo spacing $=15.6 \mathrm{~ms}, 8$ echoes, matrix size $=240$, and resolution $=0.9375 \times 0.9375 \times 2.4 \mathrm{~mm}$. In addition, hippocampus tracings were performed in according to with our another study, ${ }^{22}$ with the GE Volume Viewer voxtool 4.2 program and to with standard anatomic atlases. ${ }^{23,24}$ For MRS evaluations, the method administered by Bertolino et al. ${ }^{25}$ was used. Afterwards, NAA, CRE, and CHO levels were investigated. NAA, CHO, and CRE peaks were determined automatically for all voxels which were included within the hippocampus. Otherwise they were removed. Consequently, for only on voxels containing ${ }^{1} \mathrm{H}$ spectra, final calculations were carried out. Position of hippocampal voxels and sample magnetic resonance spectrum are presented in Figure 1.

\section{Statistical analysis}

All analyses were conducted using the SPSS for Windows software, version 13.0 (SPSS Inc., Chicago, IL, USA). A twotailed statistical significance level was set at $\mathrm{p}<0.05$ for all anal-
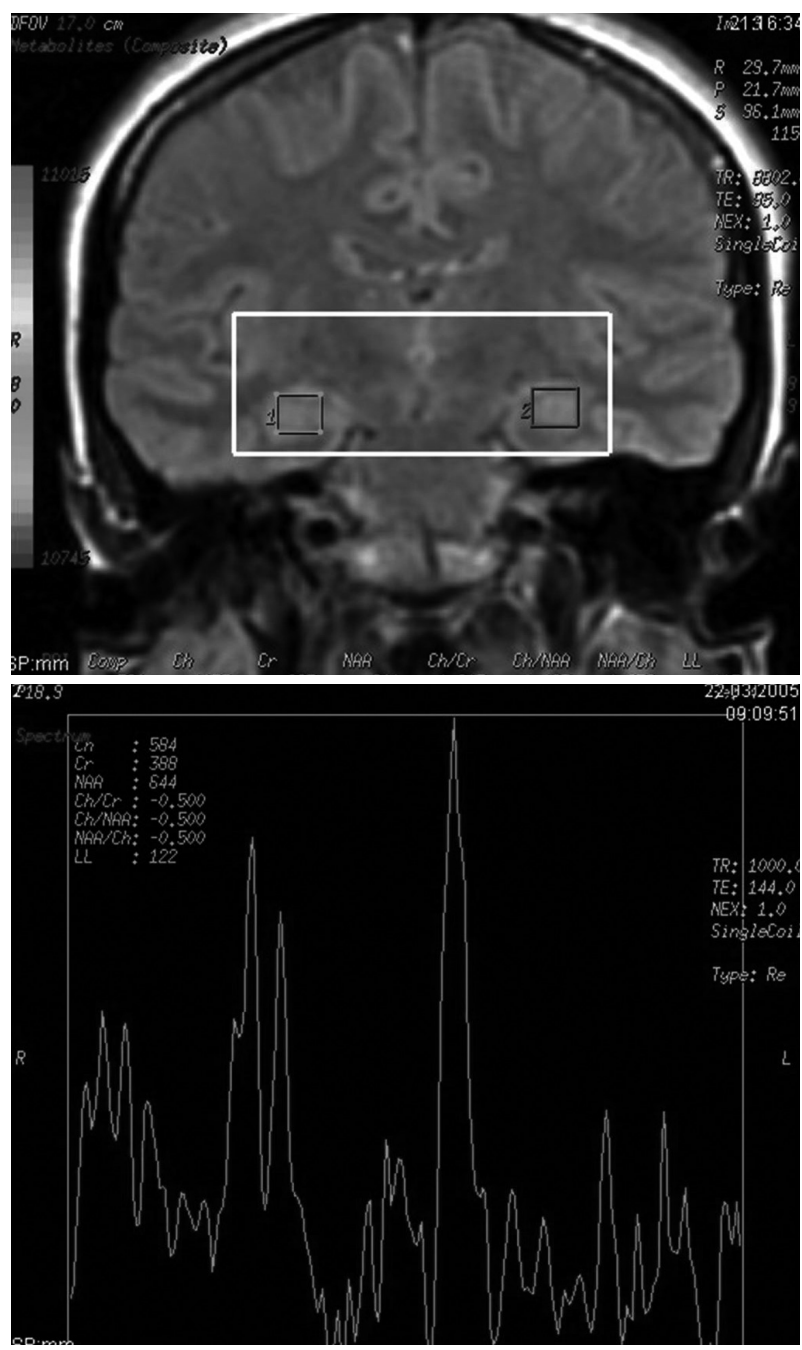

Figure 1. Position of hippocampal voxels and sample magnetic resonance spectrum. 
yses. The differences between patients and controls tested separately by a one-way analysis of variance (ANOVA), with hemisphere (left or right) as the within-group factor and diagnosis as the between-group factor were determined for metabolyte ratios. Categorical data were assessed by using chisquare test while group differences in demographic variables involving continuous data were computed using independent ttest. For correlations, Pearson's correlation test was used.

\section{RESULTS}

As presented in Table 1, there were no significant differences in demographic variables of age, gender composition, educational level, and handedness between the patients with panic disorder and comparison subjects. Furthermore, no structural abnormalities were noted qualitatively on the MRI scans of the patients or controls. It was also demonstrated the the results of hippocampus ${ }^{1} \mathrm{H}$ MRS forthe patients and healthy volunteers.

When NAA values were compared between groups, statistically significant difference was detected for both sides (patients, mean $\pm S D=430.00 \pm 252.62$; controls, mean $\pm S D=952.76 \pm$ $107.51 ; \mathrm{t}=-7.85, \mathrm{p}<0.001$ for left side; patients, mean $\pm \mathrm{SD}=$ $397.18 \pm 123.41$; controls, mean $\pm \mathrm{SD}=832.82 \pm 124.14 ; \mathrm{t}=-10.26$, $\mathrm{p}<0.001$ for right side). In regard to totally NAA, the difference was maintained (patients, mean $\pm \mathrm{SD}=827.17 \pm 330.92$; controls, mean $\pm S D=1785.59 \pm 144.03$; $\mathrm{t}=-10.95, \mathrm{p}<0.001)$. With respect to $\mathrm{CHO}$ levels, statistically significant difference was detected for both sides (patients, mean $\pm \mathrm{SD}=430.00 \pm 252.62$; controls, mean $\pm S D=952.76 \pm 107.51 ; \mathrm{t}=-7.85, \mathrm{p}<0.001$ for left

Table 1. Demographic, clinical, volumetrik and spectroscopic and ${ }^{1} \mathrm{H}$ MRS data of the patients and controls

\begin{tabular}{lcc}
\hline & Patients $(\mathrm{N}=20)$ & Controls $(\mathrm{N}=20)$ \\
\hline Age & $33.41 \pm 6.95$ & $31.71 \pm 5.58$ \\
Gender (F/M) & $10 / 8$ & $9 / 9$ \\
Duration (years) & $3.65 \pm 2.53$ & - \\
Education (years) & $8.29 \pm 3.65$ & $8.94 \pm 3.51$ \\
Handedness (right) & 20 & 20 \\
HDRS score & $11.11 \pm 4.78$ & $5.82 \pm 2.40^{*}$ \\
Hippocampus volume $\left(\mathrm{mm}^{3}\right)$ & & \\
$\quad$ Left & $3060.32 \pm 390.64$ & $2987.72 \pm 266.72$ \\
$\quad$ Right & $3123.03 \pm 299.8$ & $3026.14 \pm 237.09$ \\
NAA & $827.17 \pm 330.92$ & $1785.59 \pm 144.03^{*}$ \\
CHO & $946.24 \pm 451.80$ & $1725.24 \pm 145.92^{*}$ \\
CRE & $641.35 \pm 246.41$ & $1269.24 \pm 130.39^{*}$ \\
\hline
\end{tabular}

No significant differences exist between groups in age, handedness, education, and gender composition. ${ }^{*} \mathrm{p}<0.001$. F: female, $\mathrm{M}$ : Male, HDRS: Hamilton Depression Rating Scale, NAA: N-acetyl aspartate, $\mathrm{CHO}$ : choline, CRE: creatine, ${ }^{1} \mathrm{H}$ MRS: proton magnetic resonance specroscopy side; patients, mean $\pm \mathrm{SD}=397.18 \pm 123.41$; controls, mean $\pm \mathrm{SD}=$ $832.82 \pm 124.14 ; \mathrm{t}=-10.26, \mathrm{p}<0.001$ for right side). The difference for total $\mathrm{CHO}$ was maintained (patients, mean $\pm \mathrm{SD}=$ 827.17 \pm 330.92 ; controls, mean $\pm S D=1785.59 \pm 144.03 ; \mathrm{t}=-10.95$, $\mathrm{p}<0.001)$. As for the CRE values, same diferences were detected. The mean CRE levels of the patient group was statistically significant lower compared to that of control ones (patients, mean $\pm S D=430.00 \pm 252.62$; controls, mean $\pm S D=952.76 \pm$ $107.51 ; \mathrm{t}=-7.85, \mathrm{p}<0.001$ for left side; patients, mean $\pm \mathrm{SD}=$ $397.18 \pm 123.41$; controls, mean $\pm \mathrm{SD}=832.82 \pm 124.14 ; \mathrm{t}=-10.26$, $\mathrm{p}<0.001$ for right side). Likewise, total CRE was lower in the patients than control subjects (patients, mean $\pm \mathrm{SD}=827.17 \pm$ 330.92; controls, mean $\pm \mathrm{SD}=1785.59 \pm 144.03$; $\mathrm{t}=-10.95, \mathrm{p}<0.001$ ). When general linear model was used, age and TBV corrected NAA levels were significantly lower in patients compared to controls, with a main effect of diagnosis ( $\mathrm{F}=10.24, \mathrm{p}=0.003)$ and without a main effect of age $(\mathrm{F}=1.43, \mathrm{p}=0.24)$ and TBV $(\mathrm{F}=2.04, \mathrm{p}=$ $0.16)$. In addition, $\mathrm{CHO}$ values were significantly lower in the patients compared to controls, with a main effect of diagnosis $(\mathrm{F}=5.70, \mathrm{p}=0.024)$ and without a main effect of age $(\mathrm{F}=0.14$, $\mathrm{p}=0.71)$ and TBV $(\mathrm{F}=0.021, \mathrm{p}=0.89$ ). Likewise, $\mathrm{CRE}$ values were significantly lower in patients compared to controls, with a main effect of diagnosis ( $\mathrm{F}=13.03, \mathrm{p}=0.001)$ and without a main effect of age $(\mathrm{F}=0.39, \mathrm{p}=0.54)$ and TBV $(\mathrm{F}=0.59, \mathrm{p}=0.45)$. The mean hippocampus NAA/CRE ratio of the patients did not differ to that of control subjects (patients, mean $\pm S D=1.34 \pm 0.35$; controls, mean $\pm \mathrm{SD}=1.42 \pm 0.18$; $\mathrm{t}=-0.81, \mathrm{p}=0.42$ ). Likewise, $\mathrm{NAA} /$ $\mathrm{CHO}$ ratio of the patients with panic disorder did not differ that of the control subjects, as determined by unpaired t test (patients, mean $\pm S D=0.93 \pm 0.24$; controls, mean $\pm S D=1.04 \pm 0.10$; $\mathrm{t}=-0.64, \mathrm{p}=0.11)$. On the other hand, no significant difference was detected between groups in regard to $\mathrm{CHO} / \mathrm{CRE}$ ratio (patients, mean $\pm \mathrm{SD}=1.46 \pm 0.27$; controls, mean $\pm \mathrm{SD}=1.37 \pm$ $0.18 ; \mathrm{t}=1.06, \mathrm{p}=0.29)$. NAA, $\mathrm{CHO}$, or CRE values were did not correlate with hippocampus volumes, HDRS or PAS scores.

\section{DISCUSSION}

In the present study, we found some important findings. When NAA, CHO and CRE values were compared between groups, statistically significant lower levels for all ones were detected for both sides. This change is independent of volumes because of the fact that there was no volume difference between groups for both sides and that no correlation was found between NAA, CHO, or CRE values and hippocampus volumes. At this point, we require to mention about our previous investigations in a variety of psychiatric disorders on NAA. In the other studies of ours, it was showed that NAA might also play an important role on the pathophyiology of bipolar disorder and obsessive compulsive disorder (OCD), and on the neuroprotec- 
tive effect of quetiapine. ${ }^{26-28}$ These findings are very important since the role of NAA is established in neuronal integrity. Disablement in neuronal integrity may be associated with a neurodegenerative process and this may be related to the pathogenesis of panic disorder. Despite several investigations in patients with panic disorder revealed inconsistent results, dysregulation of the hypothalamic-pituitary-adrenal (HPA) axis may play a role in panic disorder. ${ }^{14}$ Hippocampus, a glucocorticoid feedback area, is highly sensitive to endogenous glucocorticoid levels and so is an important region affected by stress modulation organized by the hypothalamo-pituitary-adrenal axis (HPA) ${ }^{15-17}$ In this context, there may be an association between HPA dysregulation and hippocampus neurochemicals. There is only one study on hippocampal neurochemicals in the patients with panic disorder. ${ }^{28}$ In their study, Trzesniak et al. ${ }^{28}$ comprised 25 panic patients and 18 healthy control subjects and found that compared with controls, panic patients demonstrated significantly lower NAA/CRE in the left hippocampus. They suggested that left hippocampal NAA/CRE in panic disorder might be reflecting neuronal loss or neuronal metabolic dysfunction in that disorder, as discussed by us.

As for the $\mathrm{CHO}$ and CRE values, we found significantly reduced levels for both neurochemicals in the patients with panic disorder in contrast to the study performed by Trzesniak et al. ${ }^{29}$ who did not detected any $\mathrm{CHO}$ difference between panic patients and healthy control subjects. On the other hand, they found significant lower NAA/CRE ratio in the right hippocampus. We did not the exact reason between the findings of their study and ours. However, some confounding factors may contribute to this discrepancy. First of all, in their study, the mean age of the patients (39.2 \pm 9.9$)$ is considerably higher than that of the present study (33.41 \pm 6.95$)$. Secondly, in their study, sixteen of the patients were receiving pharmacological treatment at the time of MRI scanning. It was shown phosphotidylcholine breakdown to have an important role in signal transduction $^{30}$ suggesting that reduced $\mathrm{CHO}$ concentrations in patients with panic disorder might contribute to the pathophysiology of the disorder by this way. Reduced CRE values were also reported by Massana et al. ${ }^{18}$ who found that the concentration of creatine and phosphocreatine was significantly lower in the right medial temporal lobe region of panic disorder patients compared to healthy subjects, without any significant differences for the medial prefrontal cortex and concluded that these results provided neurochemical evidence suggesting the involvement of the amygdalohippocampal region in the pathogenesis of panic disorder. Our same finding in the present study was important when we take into consideration that as implicated by Trzesniak et al., ${ }^{29} \mathrm{CRE}$ is thought to be relatively stable among individuals and in most brain areas; for this reason, it is often used as an internal reference. In the present study, absolute NAA, CHO, and CRE meaurements were discussed rather than metabolite ratios. The main reason why we done such a thing that NAA metabolite ratios must explain the alterations in the CRE reference peak that make out of vogue their usefulness as an internal reference for the other metabolite peaks. $^{31,32}$

Several limitations exist with the present study. First of all, our sample size is small. This may limit the generalizability of our findings to all panic patients. Second, we only evaluated hippocampal region, however, some other important anatomic regions should be incuded in ${ }^{1} \mathrm{H}$ MRS studies on panic disorder.

Consequently, in the present study we found that NAA, $\mathrm{CHO}$ and $\mathrm{CRE}$ values of the patients with panic disorder were lower than those healthy controls. Future studies involving a large number of panic patients may shed further light on the generalizability of the current findings to persons with panic disorder.

\section{REFERENCES}

1. Fontaine R, Breton G, Dery R, Fontaine S, Elie R. Temporal lobe abnormalities in panic disorder: an MRI study. Biol Psychiatry 1990;27:304310.

2. Vythilingam M, Anderson ER, Goddard A, Woods SW, Staib LH, Charney DS, et al. Temporal lobe volume in panic disorder-- a quantitative magnetic resonance imaging study. Psychiatry Res 2000;99:75-82.

3. Massana G, Serra-Grabulosa JM, Salgado-Pineda P, Gasto C, Junque C, Massana J, et al. Parahippocampal gray matter density in panic disorder: a voxel-based morphometric study. Am J Psychiatry 2003;160:566-568.

4. Massana G, Serra-Grabulosa JM, Salgado-Pineda P, Gasto C, Junque C, Massana J, et al. Amygdalar atrophy in panic disorder patients detected by volumetric magnetic resonance imaging. Neuroimage 2003;19:80-90.

5. Uchida RR, Del-Ben CM, Santos AC, Araujo D, Crippa JA, Guimaraes FS, et al. Decreased left temporal lobe volume of panic patients measured by magnetic resonance imaging. Braz J Med Biol Res 2003;36:925-929.

6. Yoo HK, Kim MJ, Kim SJ, Sung YH, Sim ME, Lee YS, et al. Putaminal gray matter volume decrease in panic disorder: an optimized voxel-based morphometry study. Eur J Neurosci 2005;22:2089-2094.

7. Protopopescu X, Pan, H, Tuescher O, Cloitre M, Goldstein M, Engelien $\mathrm{A}$, et al. Increased brainstem volume in panic disorder: a voxel-based morphometric study. Neuroreport 2006;17:361-363.

8. Fischer H, Andersson JL, Furmark T, Fredrikson M. Brain correlates of an unexpected panic attack: a human positron emission tomographic study. Neurosci Lett 1998;251:137-140.

9. Coplan JD, Lydiard RB. Brain circuits in panic disorder. Biol Psychiatry 1998,44:1264-1276.

10. Pillay SS, Gruber SA, Rogowska J, Simpson N, Yurgelun-Todd DA. fMRI of fearful facial affect recognition in panic disorder: the cingulate gyrusamygdala connection. J Affect Disord 2006;94:173-181.

11. Schunck T, Erb G, Mathis A, Gilles C, Namer IJ, Hode Y, et al. Functional magnetic resonance imaging characterization of CCK-4-induced panic attack and subsequent anticipatory anxiety. Neuroimage 2006;31:11971208.

12. Gorman M, Kent JM, Sullivan GM, Coplan JD. Neuroanatomical hypothesis of panic disorder, revised. Am J Psychiatry 2000;157:493-505.

13. Guimares AR, Schwartz P, Prakash MR, Carr CA, Berger UV, Jenkins $\mathrm{BG}$, et al. Quantitative in vivo $1 \mathrm{H}$ nuclear magnetic resonance spectroscopic imaging of neuronal loss in rat brain. Neuroscience 1995;69: 1095-1101.

14. Abelson JL, Khan S, Liberzon I, Young EA. HPA axis activity in patients 
with panic disorder: review and synthesis of four studies. Depress Anxiety 2007;24:66-76

15. Sheline YI, Wang PW, Gado MH, Csernansky JG, Vannier MW. Hippocampal atrophy in recurrent major depression. Proc Natl Acad U S A 1996; 93:3908-3913

16. Hoschl C, Hajek T. Hippocampal damage mediated by corticosteroids-a neuropsychiatric research challenge. Eur Arch Psychiatry Clin Neurosci 2001;251(Suppl 2):II81-II88.

17. Mizoguchi K, Ishige A, Aburada M, Tabira T. Chronic stress attenuates glucocorticoid negative feedback: involvement of the prefrontal cortex and hippocampus. Neuroscience 2003;119:887-897.

18. Massana G, Gastó C, Junqué C, Mercader JM, Gómez B, Massana J, et al. Reduced levels of creatine in the right medial temporal lobe region of panic disorder patients detected with (1)H magnetic resonance spectroscopy. Neuroimage 2002;16:836-842.

19. Corapçıŏlu A, Aydemir O, Ylldız M. DSM-IV Eksen I Bozuklukları (SCID-I) İçin Yapılandırılmış Klinik Görüşme, Klinik Versiyon. Ankara: Hekimler Yayın Birliği; 1999.

20. Hamilton M. Development of a rating scale for primary depressive illness. Br J Soc Clin Psychol 1967;6:278-296.

21. Bandelow B. Assessing the efficacy of treatment for panic disorder and agoraphobia. II. The Panic and Agoraphobia Scale. Int Clin Psychopharmacol 1995;10:73-81.

22. Atmaca M, Sirlier B, Yildirim H, Kayali A. Hippocampus and amygdalar volumes in patients with somatization disorder. Prog Neuropsychopharmacol Biol Psychiatry 2011;35:1699-1703.

23. Duvernoy HM, Cabanis EA. The Human Brain: Surface, Three-Dimen- sional Sectional Anatomy, and MRI. New York: Springer-Verlag; 1991.

24. Talairach J, Tournoux P. Co-planar Stereotaxic Atlas of the Human Brain. New York: Thieme Medical Publishers; 1998.

25. Bertolino A, Frye M, Callicott JH, Mattay VS, Rakow R, Shelton-Repella J, et al. Neuronal pathology in the hippocampal area of patients with bipolar disorder: a study with proton magnetic resonance spectroscopic imaging. Biol Psychiatry 2003;53:906-913.

26. Atmaca M, Yildirim H, Ozdemir H, Poyraz AK, Tezcan E, Ogur E. Hippocampal 1H MRS in first-episode bipolar I patients. Prog Neuropsychopharmacol Biol Psychiatry 2006;30:1235-1239.

27. Atmaca M, Yildirim H, Ozdemir H, Ogur E, Tezcan E. Hippocampal $1 \mathrm{H}$ MRS in patients with bipolar disorder taking valproate versus valproate plus quetiapine. Psychol Med 2007;37:121-129.

28. Atmaca M, Yildirim H, Ozdemir H, Koc M, Ozler S, Tezcan E. Neurochemistry of the hippocampus in patients with obsessive-compulsive disorder. Psychiatry Clin Neurosci 2009;63:486-490.

29. Trzesniak C, Uchida RR, Araújo D, Guimarães FS, Freitas-Ferrari MC, Filho AS, et al. (1) H magnetic resonance spectroscopy imaging of the hippocampus in patients with panic disorder. Psychiatry Res 2010;182:261265.

30. Exton JH. Phophatidylcholine breakdown and signal transduction. Biochim Biophys Acta 1994;1212:26-42.

31. Deicken RF, Pegues MP, Anzalone S, Feiwell R, Soher B. Lower concentration of hippocampal $\mathrm{N}$-acetylaspartate in familial bipolar I disorder. Am J Psychiatry 2003;160:873-882.

32. Ross B, Michaelis T. Clinical applications of magnetic resonance spectroscopy. Magn Reson Q 1994;10:191-247. 